\title{
Los tres ejes autonómicos de la política exterior de Brasil (2003-2013) ${ }^{1}$
}

The three autonomic axes of Brazil foreign policy (2003-2013)

Esteban Actis ${ }^{2}$

\section{RESUMEN}

El presente artículo tiene como objetivo analizar la política exterior brasileña reciente (2003-2013) a partir del tradicional concepto de autonomía. Como evidencia el artículo, para lograr un mayor margen de maniobra en el sistema internacional la política exterior de Brasil se sustentó en tres estrategias o ejes autonómicos como el soft balancing, la unidad colectiva y la diversificación de relaciones exteriores.

Palabras clave: autonomía, política exterior, Brasil.

\section{ABSTRACT}

This article analyses the current Brazilian foreign policy (2003-2013) based on the traditional concept of autonomy. As evidence the article to achieve a greater margin of maneuver in the international system, Brazil's foreign policy was based on three autonomics strategies or axes: the soft balancing, collective unity and the diversification of foreign relations.

Key Words: autonomy, foreign policy, Brazil.

\section{Introducción.}

La autonomía es sin lugar a dudas el aspecto más sobresaliente en la idea de continuidad de la política exterior Brasileña (Gomes Saraiva, 2012). Brasil ha sido el país de América Latina donde la "lógica de la autonomía" como "gran estrategia de política externa" (Russell \& Tokaltian,2013) ha tenido mayor apego. La idea de la autonomía no fue abandonada inclusive en aquellos momentos donde la política exterior

\footnotetext{
${ }^{1}$ Artigo recebido em 25 de fevereiro de 2014 e aprovado em 31 de março de 2014.

${ }^{2}$ Doctorando y graduado en Relaciones Internacionales por la Facultad de Ciencia Política y Relaciones Internacionales de la Universidad Nacional de Rosario - UNR, Argentina. Docente de la Cátedra de "Política Internacional Latinoamericana" en la misma casa de estudio, Becario Doctoral del Consejo Nacional de Investigaciones Científicas y Técnicas (CONICET)
}

Conjuntura Global, Vol.3, n.1, jan./mar., 2014, p. 21-27. 
dejo de lado la tradicional postura "globalista" y abrazó las ideas liberales y americanista (Merke,2008; Pinheiro,2000)

La noción de autonomía debe ser entendida como una situación opuesta a la de la dependencia, de acuerdo a la famosa teorización de Juan Carlos Puig (1984). Sintéticamente la autonomía puede ser definida como "la capacidad y disposición del Estado para tomar decisiones basadas en necesidades y objetivos propios sin interferencia ni constreñimientos externos" (Russell \& Tokatlian,2001). En otras palabras, una política exterior autónoma no subordina los objetivos de política externa a los de un tercer actor. La noción de autonomía está arraigada a la histórica tendencia de la política exterior brasileña de evitar acuerdos y compromisos que limiten las futuras opciones externas. La autonomía tiene como fin último romper la condición subordinada de América Latina en el sistema internacional.

Ahora bien, las estrategias de Brasil para obtener una mayor libertad de maniobra en el sistema internacional han ido cambiando en las últimas décadas. La misma ha transitado de una "autonomía por la distancia" en los años ochenta (la última etapa del gobierno militar y el gobierno democrático de Sarney), a otra en los años noventa (cuya máxima expresión fue el gobierno de Fernando Henrique Cardoso) denominada "autonomía por la participación". Desde el 2003 la autonomía pueda conceptualizarse como “autonomía por la diversificación” (Vigevani \& Cepaluni, 2007).

Si bien una de las principales características de la lógica autonómica de la política exterior de Brasil durante el gobierno de Lula (2003-2010) y los dos primeros años de Dilma Rousseff (2011-2013) ha sido la diversificación de las relaciones exteriores, la misma es solo uno de los tres ejes en la cual se sustentó el intento de ampliar el margen de maniobra de Brasil en el sistema internacional. Esta ha sido acompañada por la estrategia de la "unidad colectiva" y el "equilibrio blando o soft balancing"

\footnotetext{
${ }^{3}$ La "autonomía por la distancia" tiene un carácter defensivo, al no aceptar automáticamente los regímenes internacionales prevalecientes, aspira a una economía volcada al mercado interno y una postura de contraposición de la agenda de las grandes potencias para preservar la soberanía nacional, la "autonomía por la participación" cree en que la adhesión a los regímenes internacionales, inclusive los de carácter liberal, no conlleva una perdida en la capacidad de gestión del Estado, todo lo contrario, se puede influenciar la propia formulación de las reglas en el sistema internacional. Por último, en la autonomía por la diversificación la adhesión a las normas y principios internacionales está dada por alianzas de tipo SurSur y coaliciones con aliados no tradicionales dado que a partir de ello se reduce la asimetría con el tradicional mundo desarrollado.
}

Conjuntura Global, Vol.3, n.1, jan./mar., 2014, p. 21-27. 


\section{Los tres ejes de la política exterior autónoma de Brasil bajo el gobierno de Lula}

La "lógica de la autonomía" derivó en cuatro opciones estratégicas principales a las que recurrieron los países latinoamericanos por más de cien años: el equilibrio blando, la diversificación de las relaciones exteriores, la unidad colectiva y el repliegue. Salvo esta última opción ${ }^{4}$, el accionar externo de Brasil entre 2003 y 2010 utilizó las tres primeras estrategias para intentar ganar mayores márgenes de maniobra en el escenario internacional

El soft balancing consiste en la utilización de las instituciones internacionales y de instrumentos legales y diplomáticos para frustrar o restringir el uso abusivo del poder y las acciones agresivas de las grandes potencias, así como para defender o hacer valer intereses propios. La unidad colectiva busca aumentar la integración, cooperación y concertación entre los países latinoamericanos con el propósito de aunar fuerzas y robustecer la capacidad de negociación individual y grupal. Por último, la diversificación procura multiplicar los lazos externos con el objeto de contrarrestar y compensar la dependencia de una sola contraparte altamente dotada de recursos y con gran capacidad de influencia (Russell \& Tokalian (2013:162)

La puesta en práctica de estas tres estrategias posibilitaron que Brasil haya alcanzado dura entre 2003 y 2013 "un mayor nivel de responsabilidad, presencia y participación en el plano global" (Gomes Saraiva \& Valencia, 2011:102), en otras palabras "haya elevado su status a jugador global" (Tursi,2013).

El soft balancing ha sido una estrategia central del relacionamiento externo brasileño desde el 2003. Ejemplos de este estrategia ha sido la formación de coaliciones con otras potencias medias como BRIC (Flemes,2010) o en IBSA (Giacagglia,2010) y en

\footnotetext{
${ }^{4}$ La opción del repliegue no fue una estrategia de la reciente política exterior brasileña. El repliegue implica la resistencia a asumir compromisos de naturaleza militar, a integrar alianzas bélicas 0 a participar en conflictos externos o disputas diplomáticas extrarregionales que pudieran generar altos costos o el involucramiento en asuntos internacionales considerados ajenos a los intereses nacionales (Russell \& Tokalian (2013:162). Por ejemplo, el acuerdo de Cooperación Militar entre Brasil y EEUU firmado en 2010 y el activo rol diplomático de Brasil en el intento de mediación, junto con Turquía, entre las potencias occidentales e Irán por el plan nuclear persa, son hechos que no se ajustan a una política de repliegue.
}

Conjuntura Global, Vol.3, n.1, jan./mar., 2014, p. 21-27. 
la formación de coaliciones al interior de organizaciones internacionales como la OMC (Amorim,2010). El tema de las coaliciones ha sido central en la política exterior desde el 2003, incluso algunos académicos mencionan que la autonomía en este período también puede catalogarse como “autonomía por la coalición” (Pereira Doval,2013). Otra acción que se encumbra dentro de este eje, ha sido la constante búsqueda de lograr injerencia en organismos internacionales mediante la promoción de candidatos brasileños. La elección de Roberto Azevedo en la Organización Mundial del Comercio y José Graziano Da Silva en la Organización de las Naciones Unidas para la Alimentación y la Agricultura (FAO) son más que elocuentes son claros ejemplos. Asimismo, deben mencionarse otros casos de menor impacto mediático, pero de mucha importancia para la diplomacia brasileña. Desde 2011, los brasileños Robério Oliveira Silva, Bráulio Ferreira de Souza Dias, Roberto Figueiredo Caldas e Paulo de Tarso Vannuchi, fueron electos o designados para cargos en instituciones multilaterales ${ }^{5}$.

A su vez, toda política exterior que se jacte de ser autónoma, debe inexorablemente evitar cualquier "alineamiento" con otro actor en el plano internacional. Motivo por el cual, la autonomía está relacionada a una visión universalista, entendida esta como la voluntad de mantener relaciones con todos los países, independientemente de su localización geográfica, tipo de régimen político y orientación económica, así también como la independencia de acción en relación a los poderes globales (Saraiva,2011:54). En materia político/diplomático desde 2003 fueron creados 77 nuevos puestos en el exterior. Actualmente el Ministerio de Relaciones Exteriores cuenta con una red de 227 puestos. En diciembre de 2011, Brasil se convirtió en uno de los doce países del mundo que mantienen relaciones diplomáticas con todos los demás miembros de la ONU (Patriota,2013). Los datos indican que entre 2003 y 2013 se crearon 1/3 del total de los puestos diplomáticos que cuenta Brasil en la actualidad. La búsqueda de nuevas parceiras estratégicas con el denominado "Sur" ha sido una constante en el reciente relacionamiento externo de Brasil. En ese marco debe destacarse la "revalorización" de África por parte del gobierno de Lula (Lechini,2008).

\footnotetext{
${ }^{5}$ Oliveira Silva fue electo para el cargo de director-ejecutivo da Organización Internacional del Café en septiembre de 2011. Souza Días fue designado para el cargo de secretario-ejecutivo de la Convención sobre Diversidad Biológica en enero de 2012. Figueiredo Caldas fue electo para la Corte Interamericana de Derechos Humanos en enero de 2012. Por último, Vannuchi remplazó a Caldas en enero de 2013.
}

Conjuntura Global, Vol.3, n.1, jan./mar., 2014, p. 21-27. 
Por último, Brasil profundizó desde el 2003 la política de integración sudamericana iniciada por sus predecesores. La búsqueda implícita de un liderazgo regional fue una constante de la diplomacia brasileña. El liderazgo en iniciativas regionales como la Comunidad Sudamericana de Naciones devenida UNASUR, en la creación del primer organismo regional abarcado a temas de defensa (Consejo Sudaméricano de Defensa) son ejemplos concretos de la importancia que le otorga Brasil a una "unidad colectiva sudamericana". Como bien señaló Marco Aurelio García, "Brasil en un mundo multipolar, no quiere ser un solo polo de poder, sino un polo de poder con sus vecinos"6. Cabe recordar que la definición de "Unidad Colectiva" indica que uno de los objetivos radica en aunar fuerzas y robustecer la capacidad de negociación individual y grupal. Ejemplos de este objetivo han sido el liderazgo brasileño en impulsar los diálogos birregionales con los países africanos, las Cumbre ASA (América del Sur-África) y con los países Árabes (Cumbre ASPA, América del Sur-Países Árabes).

\section{Reflexiones finales}

Desde los años ochenta del pasado siglo, la literatura latinoamericana en Relaciones Internacionales ha teorizado sobre la problemática de la autonomía en las políticas exteriores de la región. A la par, puede afirmarse que en la práctica Brasil ha sido el país de América Latina donde la autonomía como lógica de acción externa ha tenido mayor sustancia dado la perdurabilidad en el tiempo. En este marco, el presente artículo analizó los ejes autonómicos de la actual política exterior brasileña (2003-2013) a partir de la conceptualización de los académicos argentinos Roberto Russell y Juan Gabriel Tokatlian. La evidencia empírica muestra que la búsqueda de la autonomía estuvo dada a partir de tres estrategias o ejes de la acción externa brasileña: el soft balancing, la unidad colectiva y la diversificación de relaciones exteriores. La puesta en práctica de dichos ejes posibilitó -en orden internacional en plena mutación- un mayor protagonismo de Brasil en los asuntos internacionales, transformándose el gigante sudamericano en un jugador global.

\section{Referencias bibliográficas}

\footnotetext{
6 Declaraciones realizadas en la Conferencia Nacional “2003-2013: Una nueva política externa”, 16 de Julio de 2003, Universidad Federal del ABC.
}

Conjuntura Global, Vol.3, n.1, jan./mar., 2014, p. 21-27. 
Amorim, Celso. Brazilian Foreign Policy under President Lula (2003-2010): an overview. Rev. Bras. Polít. Int, Vol. 53 (special edition), pp. 214-240, 2010.

Flemes, Daniel. O Brasil na iniciativa BRIC: soft balancing numa ordem global em mudança?. Rev. Bras. Polít. Int. 53 (1): 141-156, 2010.

Giaccaglia, Clarisa. El accionar de India, Brasil y Sudáfrica (IBSA) en las negociaciones mundiales en materia de salud. La cuestión de las patentes farmacéuticas. Papel Político, Bogotá, Vol. 15, №1, pp. 285-305, 2010.

Gomes Saraiva, Miriam, "La política exterior de Dilma Rousseff hacia América del Sur: Continuidad en estrategias y ajustes en prioridades", En Andrés Serbin, Laneydi Martínez y Haroldo Ramanzini Júnior, coordinadores, El regionalismo "post-liberal" en América Latina y el Caribe: Nuevos actores, nuevos temas, nuevos desafíos .Buenos Aires, Coordinadora Regional de Investigaciones Económicas y Sociales, 2012

Gomes Saraiva, Miriam. Brazilian Foreign Policy: casual beliefs in formulation and pragmatism in practice. In Gian Luca Giardini and Peter Lambert (Ed) Latin American Foreign Policies: Between Ideology and Pragmatism. New York, Palgrave Macmillan, 2011.

Gomes Saraiva, Miriam. y Valença, Marcelo. Brasil: potencia regional con intereses globales", Revista Dialogo Político, Buenos Aires, Año XXVIII - No 4, pp. 100119. 2011

Lechini, Gladys. O Brasil na África ou a África no Brasil?: A construção da política africana pelo Itamaraty". Revista Nueva Sociedad $\mathrm{N}^{\circ}$ Especial em portugues, pp. 55 a 71, 2008.

Merke, Federico. Identidad y Política Exterior en la Argentina y Brasil. Disertación doctoral. FLACSO, Argentina, 2008.

Patriota, Antonio. Diplomacia e democratização. Revista Política Externa, Madrid, Vol. 22 nํ 2, 2013.

Pereyra Doval, Gisela. La Autonomía como eje rector de la política exterior. El caso brasileño, Revista Temas y Debates, Rosario, Ano, 17, Nㅜ25, pp. 109-125, 2013. 
Pinheiro, Letícia. Traídos pelo desejo: um ensaio sobre a teoria e a práctica da política externa brasileira contemporânea. Contexto Internacional, Rio de Janeiro, vol 22, no 2, pp. 305-335, 2000

Puig, Juan Carlos. Introducción, en Puig, J.C (comp.), América Latina: Políticas Exteriores Comparadas, Tomo I, Buenos Aires, GEL, 1984.

Russell, Roberto y Tokatlian, Juan Gabriel. América Latina y su gran estrategia: entre la aquiescencia y la autonomía. Revista CIDOB d'Afers Internacionals, Barcelona, $\mathrm{N}^{\circ}$ 104, pp. $157-180,2013$.

Russell, Roberto y Tokatlian, Juan Gabriel. De la Autonomía Antagónica a la Autonomía Relacional: una mirada teórica desde el Cono Sur. Posdata Revista de Reflexión y Análisis Político, Buenos Aires, № 7, 2001

Tursi, Mariano. Brasil juega con los grandes. Le Monde diplomatique, edición Cono Sur, Buenos Aires, Edición Nro 168, 2013.

Vigevani, Tullo y Cepaluni, Gabriel. A política externa de Lula da Silva: a estratégia da autonomia pela diversificação. Contexto Internacional, Rio de Janeior, Vol. 29, № 2, pp. 273-335, 2007. 